\title{
Vitamin D and Vascular Calcification in Chronic Kidney Disease
}

\author{
Mariano Rodriguez Julio Manuel Martinez-Moreno \\ M. Encarnación Rodríguez-Ortiz Juan R. Muñoz-Castañeda Yolanda Almaden \\ Unidad de Investigación, Servicio de Nefrología, Red in ren, Instituto Maimónides de Investigación Biomédica de \\ Córdoba, Departamento de Medicina, Hospital Universitario Reina Sofia, Córdoba, España
}

\section{Key Words}

Vascular calcification • Vitamin D • Vitamin D analogs •

Phosphate $\cdot$ Calcium $\cdot$ Chronic kidney disease

\begin{abstract}
Vascular calcification is common in patients with chronic kidney disease (CKD) and contributes to the increased rate of cardiovascular morbidity and mortality. The mechanisms regulating vascular calcification are under investigation; it is accepted that vascular calcification is an active and complex process involving many factors that promote or inhibit calcification. Vascular smooth muscle cells undergo transformation into osteogenic cells. This transformation is being stimulated by high phosphate, and more recently the role of the calcium phosphate nanocrystals has gained attention. Experimental models of uremia and in vitro studies have shown that an excess of calcitriol accelerates vascular calcification. However, observational studies suggest that vitamin D provides a survival advantage for patients with CKD. Experimental work shows that for similar serum concentrations of calcium and phosphate paricalcitol produces less vascular calcification than calcitriol suggesting a differential effect at the cellular level. Important issues regarding the role of vitamin D compounds on vascular calcification will be commented in this review.

Copyright $\odot 2011$ S. Karger AG, Basel
\end{abstract}

\section{Vascular Calcifications in Chronic Kidney Disease}

Vascular calcification is frequent in patients with chronic kidney disease (CKD). The presence and extent of vascular calcifications are predictors of cardiovascular and all-cause mortality in stable end-stage renal disease patients on hemodialysis [1-4]. It is more likely to find vascular calcification in older diabetic patients with a long time on dialysis and abnormalities of bone and mineral metabolism [5]. Therapeutic strategies to control secondary hyperparathyroidism, such as calcium-based phosphate binders and high doses of vitamin $\mathrm{D}$, may contribute to the development of vascular calcifications [6].

The effects of vitamin D on vascular health are complex and highly dependent on the dose being administered [7]. Vitamin D compounds play a role in the regulation of many cell functions in the body; they are essential for normal bone and mineral metabolism, proliferation and differentiation of various cell types, and the immune response [8]. Undesirable effects of vitamin $\mathrm{D}$ such as an increase in calcium and phosphate may favor the development of vascular calcifications while other functions such as modulation of an inflammatory response may have a preventive effect $[9,10]$. 


\section{The Mechanisms of Vascular Calcification in CKD}

The mechanisms involved in the development of vascular calcification are being progressively elucidated through exponentially increasing the number of in vitro and in vivo studies. A detailed description of this process is beyond the scope of this review (recently revised in Sage et al. [11]). Briefly, vascular calcification is currently accepted as an actively regulated process similar to bone formation involving many complex cell-related and chemical events involving the active participation of a number of calcification inducers/promoters and inhibitors (table 1). Bone proteins are expressed in arterial tissue undergoing calcification; this reflects the changes in the phenotype of vascular smooth muscle cells (VSMCs) into osteoblast-like cells which produce calcification-regulating proteins [12-15]. This phenotypic change can be triggered by a number of different situations such as low levels of estrogens, vitamin $\mathrm{K}$, inflammation, oxidative stress, and dyslipidemia. Thus, the vascular wall has the potential to make bone, but only under certain pathological circumstances, i.e. uremia, diabetes and aging, does this potential become operational.

Through the course of vascular calcification, calcium phosphate-enriched vesicles are released from viable and apoptotic VSMCs, which serve as nidi for extracellular crystal initiation [16, 17]. Of note, Sage et al. [18] have recently shown that the calcium phosphate nanocrystals, formed in the presence of high levels of inorganic phosphate, may regulate cell differentiation and calcification gene expression independently of free inorganic phosphate. These authors suggest that the nanoparticles were endocytosed producing a release of calcium into the cytosol that may induce gene expression and apoptosis. Interestingly, Speer et al. [19] have shown that cells with an osteochondrogenic phenotype isolated from calcifying arterial media were reprogrammed to recover smooth muscle cell properties and downregulated osteochondrogenic gene upon culture in medium that favors smooth muscle cell differentiation; in addition, the phenotypic switch of the restored smooth muscle cells to the osteochondrogenic state was re-induced by inorganic phosphate.

Osteogenic transformation is accompanied by the increased expression of molecular mediators of mineralization such as collagen type II, bone sialoprotein, alkaline phosphatase, osteopontin, osteocalcin, bone morphogenetic protein 2 (BMP-2) or receptor activator of NF- $\kappa B$ ligand (RANKL), as well as the increased expression of transcription factors such as Runx $2 /$ Cbfal and osterix
Table 1. Procalcificant and anticalcificant factors of vascular calcification

\begin{tabular}{ll}
\hline Procalcificant factors & Anticalcificant factors \\
\hline Phosphate & Fetuin-A \\
Inflammatory factors & Insulin \\
Warfarin & Adiponectin \\
LDL & FGF-23/klotho \\
Glucose & BMP-7 \\
Oxidative stress & Osteopontin \\
Vitamin D & Estrogen \\
Leptin & Magnesium \\
Elastin fragmentation & NPP-1 \\
Heat shock protein 70 & HDL \\
Cathepsin S & Vitamin K \\
RANKL/osteoprotegerin & ANK \\
BMP-2 & IGF-1 \\
BMP-4 & PTH \\
Calcium & PTHrP \\
Msx2 & Pyrophosphate \\
Osteocalcin & \\
Runx2/Cbfa1 & \\
Uremic toxins & \\
Alkaline phosphatase & \\
Osterix & \\
Sox9 & \\
Collagen & \\
\hline
\end{tabular}

$\mathrm{BMP}=$ Bone morphogenetic protein; FGF-23 = fibroblast growth factor 23; LDL = low-density lipoprotein; HDL = highdensity lipoprotein; RANKL = receptor activator of NF- $\mathrm{B}$ ligand; NPP-1 = pyrophosphatase/phosphodiesterase; $\mathrm{PTH}=$ parathyroid hormone; PTHrP = PTH-related peptide; IGF-1 = insulin-like growth factor-1; ANK = transmembrane protein.

which are specific to osteogenic cells [20] (table 1). On the other hand, the vascular wall and the serum posses endogenous factors that inhibit vascular calcification [21]; these include matrix Gla protein, fetuin-A, osteoprotegerin, BMP-7, pyrophosphate and others which ordinarily restrict biomineralization to skeletal bone (table 1). In CKD patients, factors promoting calcification prevail over those protecting against calcification, which are found to be inversely correlated with vascular calcification $[22,23]$.

The understanding of the role of the known and novel pro- and anticalcificant factors is presently attracting the attention as they might be used as markers of the process or for therapeutic purposes as targets or treatments. Davies et al. [24] showed that BMP-7 can prevent vascular calcification in CKD in an atherosclerosis mouse model. In a recent study, Kang et al. [25] evaluated the effect of 


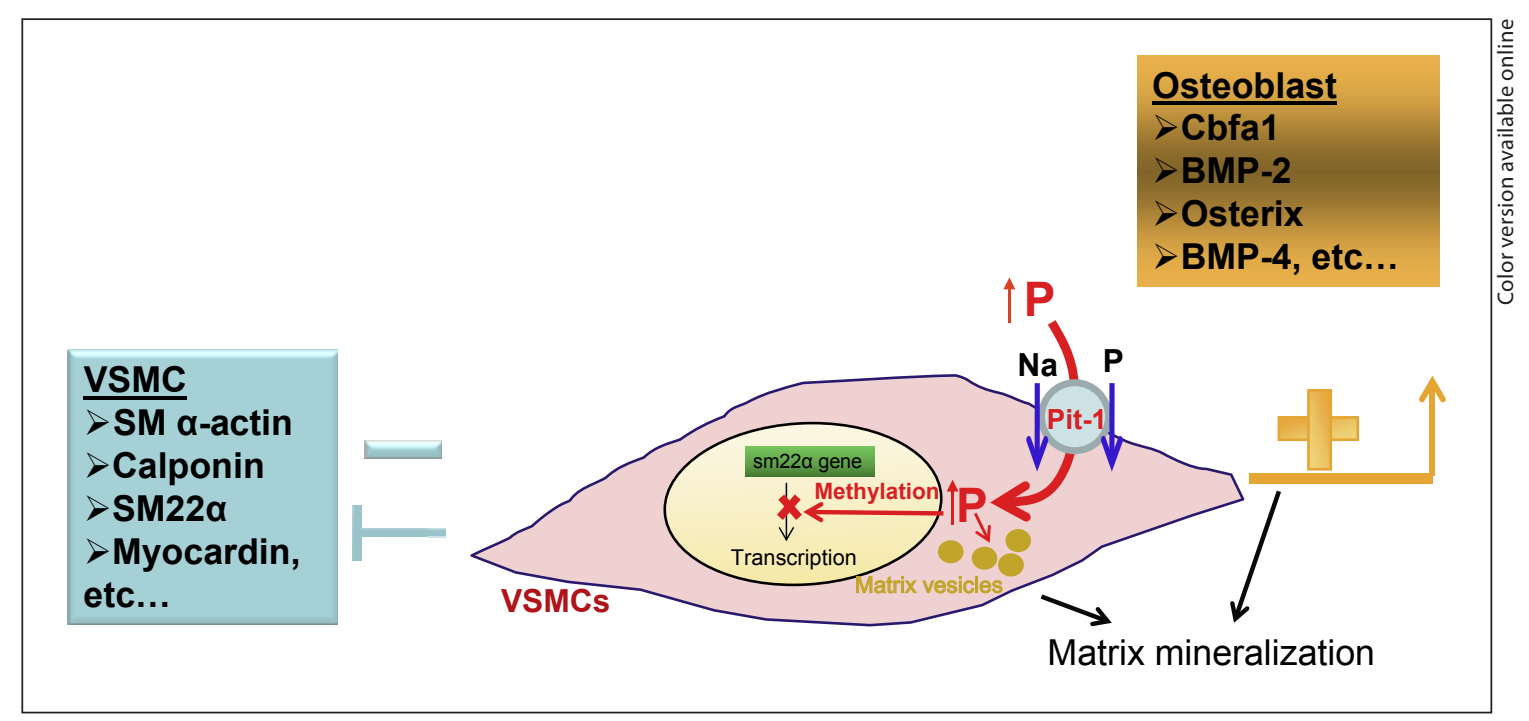

Fig. 1. Schematic representation of the effect of high phosphate levels on VSMC calcification.

recombinant human BMP-7 on vascular calcification both in vivo, in mice treated with high doses of vitamin $\mathrm{D}$, and in vitro, in human airway smooth muscle cells cultured in a high phosphate concentration. The results indicated that BMP-7 may inhibit the progression of vascular calcification induced by conditions such as high levels of vitamin D or phosphate. The administration of exogenous pyrophosphate, a potent inhibitor of vascular calcification usually deficient in CKD, can inhibit uremic vascular calcification without producing adverse effects on bone [26]. The majority of dialysis patients exhibit pronounced vitamin $\mathrm{K}$ deficiency, which may impair carboxylation of the calcification inhibitor matrix Gla protein; lower levels of circulating dephospho-carboxylated matrix Gla protein may serve as a predictor of mortality in dialysis patients [27]. Of note, a vitamin $\mathrm{K}$ therapy for vascular calcification is currently evaluated.

\section{Phosphate, a Key Factor in Vascular Calcification}

Accumulation of phosphate is increasingly adopting a central role in the generation of vascular calcification associated with uremia [15]. This key effect has been demonstrated in in vitro studies, in which the elevation of $\mathrm{P}$ concentration in the medium induces a phenotypic change of VSMCs into osteoblast-like cells and a parallel increase in calcification [28, 29]; however, the mechanism governing this is not yet clear. Jono et al. [30] reported that high extracellular P concentrations induce phosphate influx into cytoplasm via the activation of the sodium-dependent phosphate co-transporter (Pit-1). Thus, phosphate may initiate calcification by increasing the activity of Pit-1, and the increased intracellular P leads to the upregulation of osteogenic genes responsible for the phenotypic transformation of the VSMCs such as Runx2, osteocalcin, and alkaline phosphatase and, eventually, for the formation of mineralization-competent extracellular matrix. In addition, increased Pit-1 in matrix vesicles promotes $\mathrm{P}$ loading of matrix vesicles, favoring the nucleation of mineral within the extracellular matrix [15]. However, very recently, Villa-Bellosta et al. [31, 32] have shown that the effect of phosphate on vascular calcification may be independent of Pit- 1 activity. Thus it is possible that high extracellular phosphate may initiate osteogenic transformation and calcification through the production of calcium-phosphate crystals. Prosdocimo et al. [33] have recently shown that increased cAMP signaling and elevated extracellular inorganic phosphate act synergistically to induce calcification, which is correlated with a progressive reduction in extracellular pyrophosphate. In an in vitro model of VSMCs, we found that high phosphate concentration $(3.3 \mathrm{mmol} / \mathrm{l})$ in the medium was associated with increased DNA methyltransferase activity and methylation of the promoter region of the smooth muscle cell-specific protein SM22 $\alpha$ (fig. 1). This was accompanied by loss of the SM22 $\alpha$, gain of the osteoblast transcription factor Cbfal, and increased alkaline phos- 
Fig. 2. Vascular calcification mechanism in CKD.

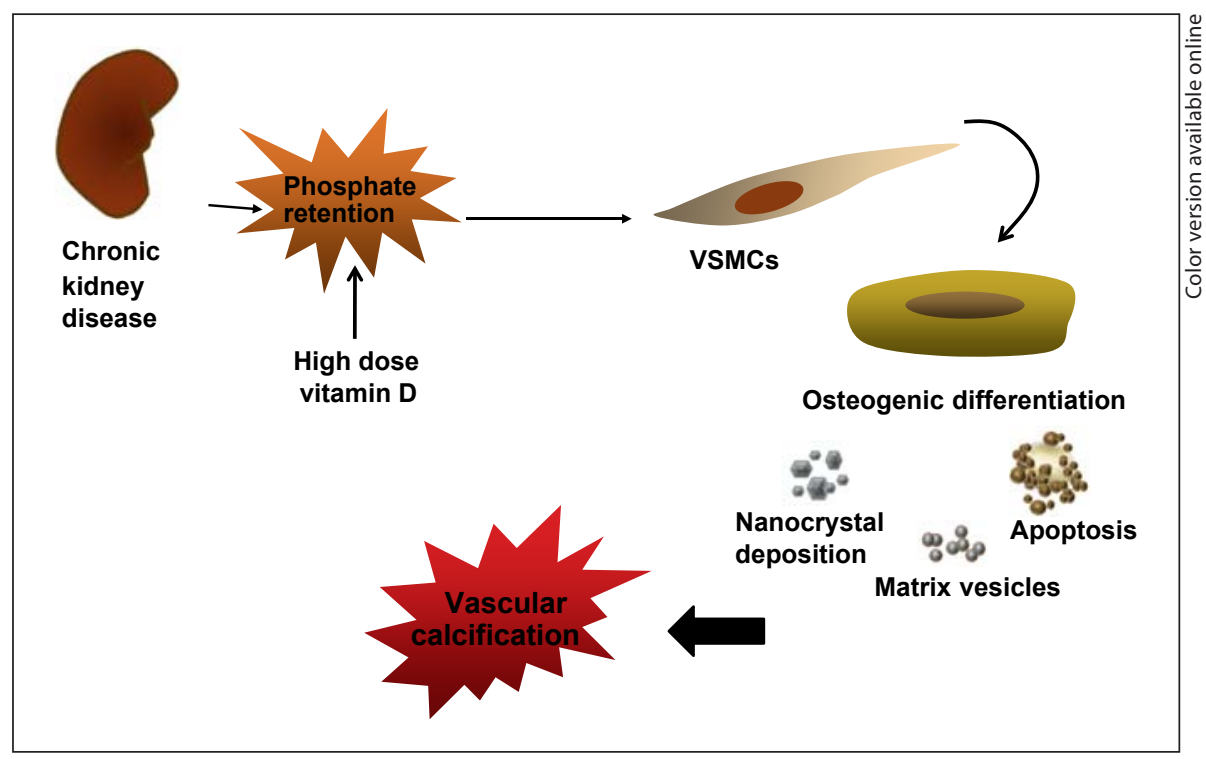

phatase activity with the subsequent in vitro calcification [34]. Taking together, these results advocate that the prevention of vascular calcifications requires strict control of phosphate levels in the uremic patients.

\section{Vitamin D and Vascular Calcification}

An apparent conflict exists between observational studies that suggest that vitamin D receptor (VDR) activators provide a survival advantage for patients with CKD and other studies showing that a high concentration of calcitriol may contribute to vascular calcification. Circulating concentrations of vitamin $D$ have been shown to be inversely correlated with vascular calcification [24] and several retrospective observational studies demonstrate an association between the administration of active vitamin D derivatives and lower relative risk of mortality in patients with CKD independent of serum $\mathrm{Ca}, \mathrm{P}$, and PTH levels [35]. Recently, Drechsler et al. [36] investigated the impact of vitamin D status on cardiovascular outcomes and fatal infections in hemodialysis and found that severe vitamin D deficiency was strongly associated with sudden cardiac death, cardiovascular events and mortality, and there were borderline associations with stroke and fatal infection. Nevertheless, numerous studies have shown that in animal models of uremia, vascular calcification appears to be accelerated by the administration of vitamin D [37-42]. Furthermore, calcitriol given to uremic rats for a short period of days at a high dose
$(1,000 \mathrm{ng} / \mathrm{kg})$ produces aortic calcifications. Interestingly, in this animal model, these changes were partially reversible several weeks after discontinuation of calcitriol administration [38]. Recently, Zebger et al. [43] observed that a high-dose calcitriol treatment induced an osteoblastic phenotype in VSMCs. This was associated with upregulation of proteins involved in mineralization and calcium transport such as osteopontin, osteocalcin, bone sialoprotein, transient receptor potential vanilloid calcium channel 6, calbindin D9K, as well as the osteogenic transcription factor osterix.

Some of the actions of vitamin D, mainly those related to the regulation of mineral metabolism, may favor vascular calcification while other effects of the vitamin D system, such as the regulation of the cell cycle and modulation of the inflammatory response, may protect the vessels from vascular calcification. Excess of calcitriol increases intestinal absorption of phosphate causing hyperphosphatemia which induces vascular calcification. The fibroblast growth factor 23 (FGF-23) null mouse model illustrates that the concomitant increase in phosphate and calcitriol results in vascular calcification. FGF-23 decreases serum phosphate concentration by inducing phosphaturia and decreases calcitriol by inhibiting renal $1 \alpha$-hydroxylase activity. The lack of FGF-23 results in hyperphosphatemia and excess of calcitriol. These rodents develop vascular calcification and survive only few weeks. Thus, the combination of high phosphate and high calcitriol produces vascular calcification (fig. 2). This is similar to what is seen in some dialysis patients with uncon- 
trolled phosphate and receiving excess amount of calcitriol to control secondary hyperparathyroidism. In a study by Stubbs et al. [44], FGF-23 null mice were fed a regular diet and diets deficient in $\mathrm{P}$ or in vitamin $\mathrm{D}$. In a low $\mathrm{P}$ diet, the serum levels of $\mathrm{P}$ were reduced but calcitriol levels remained high and these mice did not develop vascular calcification. In FGF-23 null mice, a vitamin-D-deficient diet caused a decrease in the serum calcitriol level but serum $\mathrm{P}$ remained high and vascular calcification was present. Thus, vitamin D excess may not induce calcification if phosphate is controlled.

In our laboratory, $5 / 6 \mathrm{Nx}$ rats on a high $\mathrm{P}$ diet for a couple of weeks showed moderate vascular calcification; the administration of calcitriol markedly increased vascular calcification [45]. However, the reduction to a half the dietary content of $\mathrm{P}$ prevented vascular calcification despite the same dose of calcitriol. Again high $\mathrm{P}$ is a key factor in vascular calcification associated with vitamin $D$ administration.

As VSMCs express the VDR [46], it is reasonable to assume that calcitriol, the main ligand for the VDR, has a direct effect on VSMCs and vascular calcification. Nevertheless, a direct effect of vitamin D on vascular calcification is difficult to evaluate in vivo since the administration of calcitriol results in hypercalcemia, hyperphosphatemia, and an increase in $\mathrm{Ca} \times \mathrm{P}$ product. Mizobuchi et al. [47] administrated $0.04 \mu \mathrm{g} / \mathrm{kg}$ of calcitriol intraperitoneally three times a week for 1 month; this dose of calcitriol produced medial layer calcification, but it was associated with a marked increase in serum $\mathrm{Ca}, \mathrm{P}$, and the $\mathrm{Ca} \times \mathrm{P}$ product. However, a study by Koleganova et al. [48] showed that a moderate dose of calcitriol produced vascular calcification in both sham and uremic rats. This effect was observed despite no changes in serum levels of calcium and phosphate suggesting that calcitriol may directly affect vascular calcification. In vitro studies have been performed to evaluate a direct effect of calcitriol on VSMC calcification. Jono et al. [49] showed that in VSMCs cultured with high $\mathrm{P}$, the addition of an increasing concentration of calcitriol produced a dose-dependent increase in calcium deposition. This effect of high concentration of calcitriol is associated with an increase in the RANKL/osteoprotegerin ratio [37] and the expression of osteopontin [50]. Osteoprotegerin has recently been shown as an independent predictor of mortality in CKD patients and proposed as a potential early biomarker for vascular calcification [51].

Calcitriol could induce vascular calcification through effects on bone metabolism. In patients undergoing dialysis, the low-turnover bone disease derived from low serum PTH levels is associated with vascular calcification [52]. Oversuppression of bone remodeling by calcitriol may cause vascular calcification through an imbalance of $\mathrm{Ca}$ and $\mathrm{P}$ influx into the bone [53]. Mathew et al. [54] studied the effects of the VDR activators calcitriol and paricalcitol on aortic calcification in an $\mathrm{LDLR}^{-/-}$ mouse model with CKD. Low doses of calcitriol decreased vascular calcification and this was associated with increased bone activity. These results suggest that the administration of a low dose of vitamin D analogs may protect from vascular calcification by increasing the bone activity with the incorporation of mineral to bone.

The dualistic role of vitamin $\mathrm{D}$ in vascular calcification is illustrated by the work of Shroff et al. [55], who have shown in pediatric dialysis patients that both low and high calcitriol levels were associated with increases in vascular calcification. Both the carotid intima-media thickness and calcification were increased in those patients with a low as well as with a high serum concentration of calcitriol. Interestingly, the presence of calcifications was associated with increased CRP levels, a marker of inflammation, and there was a tight negative exponential correlation between CRP and serum calcitriol levels. This clinical report shows an association between vascular calcification, calcitriol levels and inflammatory parameters.

\section{Vitamin D Analogs and Vascular Calcification}

The risk of inducing hypercalcemia and hyperphosphatemia with the administration of high doses of calcitriol in CKD patients led to the search for analogs that retain the effect of calcitriol on parathyroid glands while lacking the hypercalcemic and hyperphosphatemic effects [56]. New vitamin D compounds already in clinical use, which have an improved side effect profile, are limited to paricalcitol, 22-oxacalcitriol, and doxercalciferol [57].

Different experimental studies have shown that the vitamin D analog paricalcitol produces less calcification than calcitriol. This may be one of the reasons why Teng et al. [58] showed improved survival in patients treated with paricalcitol as compared with calcitriol. Mizobuchi et al. [39] showed that whereas administration of calcitriol and doxercalciferol induced vascular calcifications in uremic rats, equivalent doses of paricalcitol did not produce vascular calcification. This benefit of paricalcitol could have been explained by a less calcemic and phosphatemic effect of paricalcitol as compared with the oth- 
er analogs. However, an increase in the dose of paricalcitol, enough to produce hyperphosphatemia and hypercalcemia, did not produce vascular calcification. Thus a direct protective effect of paricalcitol on vascular calcification was suggested. In different experiments, control and uremic rats were treated with vehicle, calcitriol, paricalcitol, calcimimetic or the combination of calcimimetic plus calcitriol or paricalcitol. Equivalent doses of paricalcitol produced less calcification than calcitriol. The addition of calcimimetic to paricalcitol produced total prevention of vascular calcification and excellent control of secondary hyperparathyroidism [59]. Cardús et al. [37] showed in vivo and in vitro that calcitriol, but not paricalcitol, increased calcification of VSMCs independently of the levels of calcium and phosphate. Of note, the differential effects on calcification were accompanied by a differential activation of RANKL, which has been shown to induce vascular calcification by increasing the expression of BMP-4 [60]. Noonan et al. [61] evaluated in uremic rats with established secondary hyperparathyroidism the differential effects of paricalcitol and doxercalciferol on aortic calcification. Both of them produced a decrease in PTH and there were no differences in aortic calcium and phosphorus contents at the end of 6 weeks among sham, uremic and paricalcitol-treated uremic rats. However, in doxercalciferol-treated uremic rats, there was a significant increase in aortic calcium and P contents. Hirata et al. [40] assessed the effect of maxacalcitol, another vitamin D analog, on vascular calcification. They observed that maxacalcitol not only reduced PTH levels, but it also decreased calcium content in the aorta as compared to calcitriol-treated animals, despite the fact that both calcitriol and maxacalcitol induced a similar increase in $\mathrm{Ca} \times \mathrm{P}$ product. Additionally, in a recent study, Sugiura et al. [62] showed in a retrospective cohort study with predialysis patients with CKD that the oral administration of alfacalcidol was associated with reduced risk of cardiovascular disease. Interestingly, the beneficial effect of VDR compounds on vascular calcification may be mediated via other cell types. Li et al. [7] found that co-culture with macrophages promoted smooth muscle cell calcification, and this was inhibited by calcitriol and paricalcitol treatment; osteopontin was identified as candidate paracrine factor for the protective effect.

All these studies suggest differential effects of vitamin $D$ analogs on vascular calcification, that may be explained by distinct effects on target genes involved in the pathogenesis of cardiovascular remodeling and arterial calcifications. It has been demonstrated that the activation of the VDR by paricalcitol or 22-oxacalcitriol recruits dif- ferent coactivators from those recruited by calcitriol [63]. Different cell events after activation of the same VDR by the different analogs may explain why some analogs may not promote vascular calcification.

Finally, though the current treatment of vascular calcification is preventive and based on reducing hyperphosphatemia and hypercalcemia, a new approach is the search for specific treatments for vascular calcification. All the processes involved in the development of vascular calcification, mainly the systemic and local factors that can promote or inhibit vascular calcification, are potential therapeutic targets which are just being evaluated (see O’Neill and Lomashvili [56] for a recent revision).

\section{Conclusions}

The use of high doses of vitamin $\mathrm{D}$ with ensuing hyperphosphatemia and hypercalcemia may cause vascular calcification. Clinical and experimental work suggests that reasonable doses of vitamin D may prevent vascular calcification through modulation of the inflammatory response. Furthermore, clinical observations demonstrate that vitamin D analogs, such as paricalcitol, provide a survival benefit for patients with CKD. In vitro and in vivo studies demonstrate that the calcifications induced by high concentrations of calcitriol are not observed with the use of paricalcitol and other analogs. However, no clinical prospective study has been performed to demonstrate a beneficial effect of paricalcitol on vascular calcification.

\section{Acknowledgments}

This study was supported by the Instituto Carlos III (FIS 070287, FIS 07/0315, Red renal RD 06/0016/0007) and Junta de Andalucía $(0039 / 07,0127 / 08,0132 / 10)$. Y.A. is a senior researcher supported by the Fundacion Progreso y Salud, Consejeria de Salud (Junta de Andalucía). We thank Dr. Antonio Canalejo for helpful suggestions.

\section{Disclosure Statement}

None. 


\section{References}

$>1$ Wilson PWF, Kauppila LI, O’Donnell CJ, 15 Lau WL, Festing MH, Giachelli CM: PhosKiel DP, Hannan M, Polak JM, Cupples LA: Abdominal aortic calcific deposits are an important predictor of vascular morbidity and mortality. Circulation 2001;103:15291534.

-2 London GM, Guerin AP, Marchais S, Metivier $\mathrm{F}$, Pannier B, Adda $\mathrm{H}$ : Arterial media calcification in end-stage renal disease: impact on all-cause and cardiovascular mortality. Nephrol Dial Transplant 2003;18:17311740.

$>3$ Blacher J, Guerin AP, Pannier B, Marchais SJ, London GM: Arterial calcifications, arterial stiffness, and cardiovascular risk in endstage renal disease. Hypertension 2001;38: 938-942.

4 Rennenberg RJ, Kessels AG, Schurgers LJ, van Engelshoven JM, de Leeuw PW, Kroon AA: Vascular calcifications as a marker of increased cardiovascular risk: a meta analysis. Vasc Health Risk Manag 2009;5:185-197.

$>5$ Vattikuti R, Towler DA: Osteogenic regulation of vascular calcification: an early perspective. Am J Physiol Endocrinol Metab 2004;286:E686-E696.

6 Goodman WG: The consequences of uncontrolled secondary hyperparathyroidism and its treatment in chronic kidney disease. Semin Dial 2004;17:209-216.

$>7$ Li X, Speer MY, Yang H, Bergen J, Giachelli CM: Vitamin D receptor activators induce an anticalcific paracrine program in macrophages: requirement of osteopontin. Thromb Vasc Biol 2010;30:321-326.

$>8$ Bikle DD: Vitamin D: an ancient hormone. Exp Dermatol 2010;20:7-13.

$>9$ Zitterman A, Schleithoff S Koerfer R: Vitamin D and vascular calcification. Curr Opin Lipidol 2007;18:41-46.

10 Razzaque MS: The dualistic role of vitamin D in vascular calcifications. Kidney Int 2011; 79:708-714.

11 Sage AP, Tintut Y, Demer LL: Regulatory mechanisms in vascular calcification. Nat Rev Cardiol 2010;7:528-536.

$>12$ Schoppet M, Shroff RC, Hofbauer LC, Shanahan CM: Exploring the biology of vascular calcification in chronic kidney disease: what's circulating? Kidney Int 2008;73:384390.

13 Demer LL, Tintut Y: Vascular calcification: pathobiology of multifaceted disease. Circulation 2008;117:2938-2948.

- 14 Steitz SA, Speer MY, Curinga G, Yang HY, Haynes P, Aebersold R, Schinke T, Karsenty G, Giachelli CM: Smooth muscle cell phenotypic transition associated with calcification: upregulation of Cbfal and downregulation of smooth muscle lineage markers. Circ Res 2001;89:1147-1154. phate and vascular calcification: emerging role of the sodium-dependent phosphate cotransporter PiT-1. Thromb Haemost. 2010; 104:464-470.

16 Schlieper G, Aretz A, Verberckmoes SC, Krüger T, Behets GJ, Ghadimi R, Weirich TE, Rohrmann D, Langer S, Tordoir JH, Amann K, Westenfeld R, Brandenburg VM, D'Haese PC, Mayer J, Ketteler M, McKee MD, Floege J: Ultrastructural analysis of vascular calcifications in uremia. J Am Soc Nephrol 2010;21:689-696.

17 Shroff RC, McNair R, Skepper JN, Figg N, Schurgers LJ, Deanfield J, Rees L, Shanahan CM: Chronic mineral dysregulation promotes vascular smooth muscle cell adaptation and extracellular matrix calcification. J Am Soc Nephrol 2010;21:103-112.

18 Sage AP, Lu J, Tintut Y, Demer LL: Hyperphosphatemia-induced nanocrystals upregulate the expression of bone morphogenetic protein-2 and osteopontin genes in mouse smooth muscle cells in vitro. Kidney Int 2011;79:414-422.

-19 Speer MY, Li X, Hiremath PG, Giachelli CM: Runx2/Cbfa1, but not loss of myocardin, is required for smooth muscle cell lineage reprogramming toward osteochondrogenesis. J Cell Biochem 2010;110:935-947.

20 Olgaard K, Salusky IB, Silver J: The Spectrum of Mineral and Bone Disorders in Chronic Kidney Disease. Oxford, Oxford University Press, 2010, vol 18, pp 304-307. Duan D, Koczman J, Westenfeld R, JahnenDechent W, Chen NX: Role of calcification inhibitors in the pathogenesis of vascular calcification in chronic kidney disease (CKD). Kidney Int 2005;67:2295-2304.

22 Cranenburg EC, Vermeer C, Koos R, Boumans ML, Hackeng TM, Bouwman FG, Kwaijtaal M, Brandenburg VM, Ketteler M, Schurgers LJ: The circulating inactive form of matrix Gla Protein (ucMGP) as a biomarker for cardiovascular calcification. J Vasc Res 2008;45:427-436.

23 Shroff RC, Shah V, Hiorns MP, Schoppet M, Hofbauer LC, Hawa G, Schurgers LJ, Singhal A, Merryweather I, Brogan P, Shanahan C, Deanfield J, Rees L: The circulating calcification inhibitors, fetuin-A and osteoprotegerin, but not matrix Gla protein, are associated with vascular stiffness and calcification in children on dialysis. Nephrol Dial Transplant 2008;23:3263-3271.

24 Davies MR, Lund RJ, Hruska KA: BMP-7 is an efficacious treatment of vascular calcification in a murine model of atherosclerosis and chronic renal failure. J Am Soc Nephrol 2003;14:1559-1567.

$>25$ Kang YH, Jin JS, Yi DW, Son SM: Bone morphogenetic protein-7 inhibits vascular calcification induced by high vitamin D in mice. Tohoku J Exp Med 2010;221:299-307.
21 Moe SM, Reslerova M, Ketteler M, O’Neill K,
26 O’Neill WC, Lomashvili KA, Malluche HH, Faugere MC, Riser BL: Treatment with pyrophosphate inhibits uremic vascular calcification. Kidney Int 2011;79:512-517.

-27 Schlieper G, Westenfeld R, Krüger T, Cranenburg EC, Magdeleyns EJ, Brandenburg VM, Djuric Z, Damjanovic T, Ketteler M, Vermeer C, Dimkovic N, Floege J, Schurgers LJ: Circulating nonphosphorylated carboxylated matrix gla protein predicts survival in ESRD. J Am Soc Nephrol 2011;22:387395.

28 El-Abbadi MM, Pai AS, Leaf EM, Yang HY, Bartley BA, Quan KK, Ingalls CM, Liao HW, Giachelli CM: Phosphate feeding induces arterial medial calcification in uremic mice: role of serum phosphorus, fibroblast growth factor-23, and osteopontin. Kidney Int 2009; 75:1297-1307.

29 Reynolds JL, Joannides AJ, Skepper JN, McNair R, Schurgers LJ, Proudfoot D, JahnenDechent W, Weissberg PL, Shanahan CM: Human vascular smooth muscle cells undergo vesicle-mediated calcification in response to changes in extracellular calcium and phosphate concentrations: a potential mechanism for accelerated vascular calcification in ESRD. J Am Soc Nephrol 2004; 15:28572867.

-30 Jono S, McKee MD, Murry CE, Shioi A, Nishizawa Y, Mori K, Morii H, Giachelli CM: Phosphate regulation of vascular smooth muscle cell calcification. Circ Res 2000; 87:E10-E17.

31 Villa-Bellosta R, Sorribas V: Phosphonoformic acid prevents vascular smooth muscle cell calcification by inhibiting calciumphosphate deposition. Arterioscler Thromb Vasc Biol 2009;29:761-766.

32 Villa-Bellosta R, Millan A, Sorribas V: Role of calcium-phosphate deposition in vascular smooth muscle cell calcification. Am J Physiol Cell Physiol 2011;300:C210-C220.

33 Prosdocimo DA, Wyler SC, Romani AM, O’Neill WC, Dubyak GR: Regulation of vascular smooth muscle cell calcification by extracellular pyrophosphate homeostasis: synergistic modulation by cyclic AMP and hyperphosphatemia. Am J Physiol Cell Physiol 2010;298:C702-C713.

34 Montes de Oca A, Madueño JA, MartinezMoreno JM, Guerrero F, Muñoz-Castañeda J, Rodriguez-Ortiz ME, Mendoza FJ, Almaden Y, Lopez I, Rodriguez M, AguileraTejero E: High-phosphate-induced calcification is related to SM $22 \alpha$ promoter methylation in vascular smooth muscle cells. J Bone Miner Res 2010;25:1996-2005.

35 Mizobuchi M, Ogata H, Koiwa F, Kinugasa E, Akizawa T: Vitamin D and vascular calcification in chronic kidney disease. Bone 2009;45:S26-S29. 
-36 Drechsler C, Pilz S, Obermayer-Pietsch B, Verduijn M, Tomaschitz A, Krane V, Espe K, Dekker F, Brandenburg V, März W, Ritz E, Wanner C: Vitamin D deficiency is associated with sudden cardiac death, combined cardiovascular events, and mortality in haemodialysis patients. Eur Heart J 2010;31: 2253-2261.

37 Cardús A, Panizo S, Parisi E, Fernandez E, Valdivielso JM: Differential effects of vitamin D analogs on vascular calcification. J Bone Miner Res 2007;22:860-866.

-38 Bas A, Lopez I, Perez J, Rodriguez M, Aguilera-Tejero E: Reversibility of calcitriol-induced medial artery calcification in rats with intact renal function. J Bone Miner Res 2006; 21:484-490.

-39 Mizobuchi M, Finch JL, Martin DR, Slatopolsky E: Differential effects of vitamin D receptor activators on vascular calcification in uremic rats. Kidney Int 2007;72:709-715.

40 Hirata M, Katsumata K, Endo K, Fukushima $\mathrm{N}$, Ohkawa H, Fukagawa M: In subtotally nephrectomized rats 22-oxacalcitriol suppresses parathyroid hormone with less risk of cardiovascular calcification or deterioration of residual renal function than $1,25(\mathrm{OH}) 2$ vitamin $D_{3}$. Nephrol Dial Transplant 2003;18: 1770-1776.

-41 Lopez I, Aguilera-Tejero E, Mendoza FJ, Almaden Y, Perez J, Martin D, Rodriguez M: Calcimimetic R-568 decreases extraosseous calcifications in uremic rats treated with calcitriol. J Am Soc Nephrol 2006; 17:795-804.

$\checkmark 42$ Henley C, Colloton M, Cattley RC, Shatzen E, Towler DA, Lacey D, Martin D: 1,25-Dihydroxyvitamin $\mathrm{D}_{3}$ but not cinacalcet $\mathrm{HCl}$ (Sensipar/Mimpara) treatment mediates aortic calcification in a rat model of secondary hyperparathyroidism. Nephrol Dial Transplant 2005;20:1370-1377.

43 Zebger-Gong H, Müller D, Diercke M, Haffner D, Hocher B, Verberckmoes S, Schmidt S, D'Haese PC, Querfeld U: 1,25-Dihydroxyvitamin $\mathrm{D}_{3}$-induced aortic calcifications in experimental uremia: up-regulation of osteoblast markers, calcium-transporting proteins and osterix. J Hypertens 2011;29: 339-348.
44 Stubbs JR, Liu S, Tang W, Zhou J, Wang Y, Yao X, Quarles LD: Role of hyperphosphatemia and 1,25-dihydroxyvitamin D in vascular calcification and mortality in fibroblastic growth factor 23 null mice. J Am Soc Nephrol 2007;18:2116-2124.

45 Lopez I, Mendoza FJ, Guerrero F, Almaden Y, Henley C, Aguilera-Tejero E, Rodriguez M: The calcimimetic AMG 641 accelerates regression of extraosseous calcification in uremic rats. Am J Physiol Renal Physiol 2009;296:F1376-F1385.

46 Inoue T, Kawashima H: 1,25-Dihydroxyvitamin $\mathrm{D}_{3}$ stimulates ${ }^{45} \mathrm{Ca}^{2+}$-uptake by cultured vascular smooth muscle cells derived from rat aorta. Biochem Biophys Res Commun 1988;152:1388-1394.

47 Mizobuchi M, Finch JL, Martin DR, Slatopolsky E: Differential effects of vitamin D receptor activators on vascular calcification in uremic rats. Kidney Int 2007;72:709-715.

48 Koleganova N, Piecha G, Ritz E, Schmitt CP, Gross ML: A calcimimetic (R-568), but not calcitriol, prevents vascular remodeling in uremia. Kidney Int 2009;75:60-71.

49 Jono S, Nishizawa Y, Shioi A, Morii H: 1,25-Dihydroxyvitamin $\mathrm{D}_{3}$ increases in vitro vascular calcification by modulating secretion of endogenous parathyroid hormone-related peptide. Circulation 1998;98: 1302-1306.

50 Rebsamen MC, Sun J, Norman AW, Liao JK: 1alpha,25-dihydroxyvitamin $\mathrm{D}_{3}$ induces vascular smooth muscle cell migration via activation of phosphatidylinositol 3-kinase. Circ Res 2002;91:17-24.

51 Mesquita M, Demulder A, Wolff F, Mélot C, Damry N, Dratwa M, Bergmann P: Osteoprotegerin and progression of coronary and aortic calcifications in chronic kidney disease. Transplant Proc 2010;42:3444-3449.

52 London GM, Marty C, Marchais SJ, Guerin AP, Metivier F, de Vernejoul MC: Arterial calcifications and bone histomorphometry in end-stage renal disease. J Am Soc Nephrol 2004; 15:1943-1951.

53 London GM: Awareness of vascular calcification alters mineral metabolism management. Semin Dial 2010;23:267-270.
54 Mathew S, Lund RJ, Chaudhary LR, Geurs T, Hruska KA: Vitamin D receptor activators can protect against vascular calcification. J Am Soc Nephrol 2008;19:1509-1519.

-55 Shroff R, Egerton M, Bridel M, Shah V, Donald AE, Cole TJ, Hiorns MP, Deanfield JE, Rees L: A bimodal association of vitamin D levels and vascular disease in children on dialysis. J Am Soc Nephrol 2008;19:1239-1246.

56 O’Neill WC, Lomashvili KA: Recent progress in the treatment of vascular calcification. Kidney Int 2010;78:1232-1239.

57 Cunningham J, Zehnder D: New vitamin D analogs and changing therapeutic paradigms. Kidney Int 2011;79:702-707.

58 Teng M, Wolf M, Lowrie E, Ofsthun N, Lazarus JM, Thadhani R: Survival of patients undergoing hemodialysis with paricalcitol or calcitriol therapy. N Engl J Med 2003;349: 446-456.

59 Lopez I, Mendoza FJ, Aguilera-Tejero E, Perez J, Guerrero F, Martin D, Rodriguez M: The effect of calcitriol, paricalcitol, and a calcimimetic on extraosseous calcifications in uremic rats. Kidney Int 2008;73:300-307.

60 Panizo S, Cardus A, Encinas M, Parisi E, Valcheva P, López-Ongil S, Coll B, Fernandez E, Valdivielso JM: RANKL increases vascular smooth muscle cell calcification through a RANK-BMP4-dependent pathway. Circ Res 2009; 104:1041-1048.

61 Noonan W, Koch K, Nakane M, Ma J, Dixon D, Bolin A, Reinhart G: Differential effects of vitamin $D$ receptor activators on aortic calcification and pulse wave velocity in uraemic rats. Nephrol Dial Transplant 2008;23: 3824-3830.

62 Sugiura S, Inaguma D, Kitagawa A, Murata M, Kamimura Y, Sendo S, Hamaguchi K, Nagaya $\mathrm{H}$, Tatematsu M, Kurata K, Yuzawa $\mathrm{Y}$, Matsuo S: Administration of alfacalcidol for patients with predialysis chronic kidney disease may reduce cardiovascular disease events. Clin Exp Nephrol 2010;14:43-50.

63 Issa LL, Leong GM, Sutherland RL, Eisman JA: Vitamin D analogue-specific recruitment of vitamin D receptor coactivators. J Bone Miner Res 2002;17:879-890. 